\title{
The Application of Reward and Punishment in Teaching Adolescents
}

\author{
Sri Andriani Sidin ${ }^{1, *}$ \\ ${ }^{1}$ Student of English Education Department, Postgraduate Program, Universitas Negeri Padang \\ *Corresponding author. Email: sriandrianisidin@gmail.com
}

\begin{abstract}
Behaviorism theory proposes reward and punishment to help students succeed in learning. The implementation of rewards and punishment in teaching adolescents may bring some positive impacts on students learning. This paper explores how existing literature discusses the notion of rewards and punishment in the context of learning and how the rewards and punishment could affect students' learning theoretically. This paper also reviews what sort of activities teachers can do to implement rewards and punishment in a proper way. To answer these questions, the so-called 'library research' has been conducted. This was done by browsing, reading, and critically reviewing some related secondary sources such as books, journal articles. This study found that theoritically rewards would increase students' motivation to learn and work harder. The rewards and punishment will also increase students' interest in a particular subject. This will lead to a situation where rewards can motivate students to have good performance. In conclusion, this study indicates that if implemented wisely, rewards and punishment would bring a lot of positive effects on students' motivation and performance.
\end{abstract}

\section{Keywords: reward and punishment, behaviorism theory, teaching adolescents}

\section{INTRODUCTION}

Teaching adolescents can be more difficult and challenging than teaching younger students. It is mainly because adolescents are now in their transition age from children to enter early adult period. They are in a state of vulnerability in terms of identity and psychological development. Comparing to adult students, adolescents have low acceptance to critics and punishment than reward.

The challenges of teaching adolescents could have been more for English teachers in Indonesia as English is still considered to be one of the difficult subjects by many students in Indonesia. The adolescents' identity transition state and the complexity of English subjects have made more burdens for teachers in dealing with the students. Therefore, teachers must find ways on how to handle the issues.

There are some roles a teacher can do in teaching adolescents. For example, the teacher must be a helper to the students: the teacher's praise of students' success would increase the involvement between the teacher and the students and leads to more responsible students' behavior. The teachers need to be more aware of the students' results and the process and behaviors.

Some students' problems such as lack of discipline and low motivation in learning English can hinder the success of teaching learning process. For this reason, some students do not perform well during the lessons. They sometimes do not show maximum efforts to do class projects, assignments, classwork and various tasks. Therefore, it is very essential for teachers to find ways on how to motivate their students in the classroom.

In teaching learning process, motivating students to learn is indeed a part of the challenge faced by teachers. One of the most important aspects is a good classroom condition which is related to the management of classroom during teaching and learning process. Many academics have mentioned that learning objectives are attained when students are well encouraged.

One of the strategies teachers could do to motivate their students in the class is to implement reward and penalties to the students. The reward and punishment might be vary since different teachers have different kinds of award and penalty policies, but nearly all of the teachers have a similar purpose of inspiring students to learn. [1] writes in his article that the effective system of rewards and penalty should encourage appropriate outcomes and regular participation, which are fundamental to creative learning and teaching environment.

In general, reward can be understood as one of the strategies that can increase students' interest and motivation in learning to achieve success. A proper reward also provides students positive encouragement. It will show interest and increase students' participation in everyday classroom duties and responsibilities.

Meanwhile, punishments in education are the response against a lack of discipline, so teaching and encouraging discipline are the first step to prevent punishment. Punishment is closely related to strengthening because it defines both its effects. 
Both reward and punishment are essentially used for educational purposes. They are deliberately chosen by teachers to make learning process effective. It further aims to improve students' learning achievement. A well-selected reward and punishment contribute to students' learning effectiveness.

\section{METHODOLOGY}

This paper aims to answers how existing literature discusses rewards and punishment under the following issues: a) how does literature theorize the notion of reards and punishment?; b) In what ways reward and punishment would affect students' motivation; c) what kind of activities can teachers do in implementing rewards and punishment in their classroom.

To answer these research questions, the researcher employed the so-called library research approach. This was done by browsing, reading, and critically reviewing some related secondary sources such as books, journal articles, government documents, newspapers, encyclopedia and online articles related to the topic under investigation. The collected data is subsequently analyzed by selecting, displaying and redacting to answer the research questions.

\section{RESULTS AND DISCUSSION}

This section will discuss some basic terms related to the issues of rewards and punishment in the context of teaching English to adolescents. This includes the concept of rewards and punishment, kinds of rewards and punisment, typs of rewards and punishment, and functions of rewards and punishment. This section further reviews some previous studies on the effects of rewards and punishment on students' learning acchievement.

\subsection{The nature of reward and punishment}

Reward is defined as an action or attitude to respect, in order to ensure that students successfully participate and perform well [2]. Students are rewarded for some desired outcome, while inappropriate behaviors are disregarded. Rewards may include items such as cookies, sweets, extra time off, no homework, among others.

Teachers can also use a pleasant smile, a nod of approval or a pat on the back to strengthen positive behavior. It should be praised when students have done good social or academic work and should not be overdone. All that is necessary is an easy 'Great Job, guys.' Students are aware that it is an honest appreciation and they are trying to build their behaviors and activities so that they are honored by a teacher. Praise gives a good feeling for students.

Rewards for some behaviors are tangible items. Rewards can make students happy, as [3] states that there are various advantages of rewarding students in teaching, including: firstly, students will become happy to learn and indirectly try to be the best. Secondly, the teachers and students will have a good relationship to make students feel comfortable learning. Third, it trains students to be more enthusiastic and to study. Fourth, it enhances students ' learning abilities and skills.
Happy students would lead to be successful students. To make sure that students are happy in the classroom, teachers could apply a reward and punishment system. This is intended to motivate students to learn both at schools and at home. It is generally understood that the rewards system would come with a sense of pride among students. This positive atmosphere would lead to achievement among students. In other words, the reward system has motivated them to be more successful.

The most effective rewards are those 'that are motivated the learner intrinsically. This is bacause human's action and or behavior normally derive from the desires or needs from within oneself. In other words, the actions and behavior themseleves are self-rewarding. For this reason, people actually do ot really need externally driven reward for their achievement.

Meanwhile, punishment in education is an alternative response from teachers to a lack of discipline or misbehavior. Punishment is like strengthening, because it defines both its effects. [4] states that there are two kinds of punishment, positive and negative punishment. When it comes to positive punishment, it is generally happened when a positive contingency is eliminated. "An example of this may be a penalty. It is often referred to as elimination punishment. Furthermore, negative punishment happens "when a negative contingency follows a behavior ". This is when they think of the idea of punishment. Many people sometimes refer this term to be presentation punishment.

[5] describes punishment as an action that can decrease the frequency of unwanted action or behavior. [3] outlines the benefits of punishment. The first is restricting unwanted behavior. Punishment prevents unexpected behavior from being repeated. Secondly, there is an educational reason to educate the students to behave properly. Third, punishment may increase the motivation of students to have the expected behavior. Fourth, the control of punishment to prevent undesirable behavior for students, to facilitate the learning process.

\subsection{Types of reward}

There are some types of rewards mention in the existing literature. [6], for instance, divides the reward to be positive and negative reward.

a). Positive Reward

A positive reward is an indefinite expression of appreciation, a sense of accomplishment, or conscious satisfaction. For example, you know you have done something right or have helped others to improve their day. Since the intrinsic rewards are intangible, they generally appear from the person who performs the activity or behavior. In this case, intrinsic means that the reward is inherent to the person performing the activity or behavior. As an example, your teacher gives you some cookies every time the homework is completed as a reward. In that case, you will be more likely to do the homework and repeat this actions in the future, thus enhancing the behavior of completing the homework. 


\section{b). Negative Reward}

The elimination of an unpleasant reinforcement can also reinforce behavior. This is referred to negative reinforcement because it removes an adverse stimulus that rewards the animal or person. Negative reinforcement strengthens behavior because an unpleasant experience is stopped or removed. If the students do not complete the homework, for instance, giving some cookies to the teacher might change the students' perception. So in the future, the students will complete the homework to avoid giving some cookies, thus strengthening on homework's behavior.

Moreover, [7] regards reward or reinforcement is an endeavor teachers can do to increase the frequency or a behavior rate of the students by means of showing or introducing a short stimulus after dispalying the behavior. An activity that intensifies the possibility of the behavior changes is referred as a reinforcement.

There are two types of reinforcers: positive reinforcers and negative reinforces. Positive reinforcers are favorable encouragement that are given after the behavior has been shown. Through the addition of something, positive reinforcement strengthens the probability of a behavior. Example: You have been studying hard and have an $\mathrm{A}$ in your Math exam. By treating you to your favorite restaurant, your mother rewards you. You study hard again after this and have an A in your History exam as well. By going with you to see a movie you like, your mom rewards you.For your next examination, you study hard once more.

Negative reinforcers, on the other hand, are the reduction of unfavorable stimuli after the behavior has been shown. In the case of negative reinforcement, the behavior or response is intensified by the removal of something. Example: at 8 a.m. you leave home to drive your way to work, and you always encounter heavy traffic. You leave your home earlier than the next day, causing you to avoid heavy traffic. Leaving home earlier than 8 a.m. in the next few days and keep avoiding heavy traffic. This implies that the impact of getting to avoid heavy traffic intensifies your behavior of leaving home earlier than $8 \mathrm{am}$.

\subsection{Kinds of Rewards}

The reward system has been shown to be closely correlated to academic performance. [8] states that types of rewards include praise, symbolic rewards, token rewards and tangible and activity rewards.

\section{Praise}

The most popular form of reward is a verbal praise offered to students by the teachers; it means applauding the students when they act in a positive way. It shows that the teacher is satisfied with the achievement of the students. The display of a behavior pattern, such as perseverance, compassion, courage, or general intelligence, could be that behavior. Praise may also be used to compliment academic achievement, sporting or group accomplishments. In offering praise, it would be better to offer it immediately, so the emotional impact of the action is still visible. In addition, with praise, be specific. The teacher should let the student know the reason why those actions were admirable, then it would be meaningful for the students.

\section{Symbolic Rewards}

Symbolic rewards are rewards in the form of items reflecting an outstanding display of behavior or certain achievement. Gold star, perhaps the most typical type of symbolic reward given by the teacher. Others may include the name of the student or their pictures on a bulletin board or poster. Symbolic awards work similarly to praise the outstanding one in front of public displays of favor. The golden star or photograph on the bulletin board declares that the student has done something great. Unlike praise, symbolic awards have the potential to last longer than a single spoken word and can act as a reminder for students to uphold their good standing since it will be displayed in certain period of time and can be seen by many other students.

\section{Token Rewards}

Tokens reflect a value tangible reward or a type of currency. Tokens can be exchanged for a prize provided by the teacher. Chips and point tallies are common tokens, and they can be kept either by the teacher or by the students. A strict system for the allocation of points should be in place, and then the ethical and reasonable prizes can be redeemed. For instance, prizes could be priced for the students according to their value: a free homework pass could be worth 5 chips, while unlimited water fountain privileges could cost 15 chips for a month.

\section{Tangible and Activity Rewards}

Tangible rewards and activity rewards are prizes that the teachers deliver directly to the student, with no the step of symbols or tokens in between. It is a positive behavior or accomplishment award for the students with desirable achievement. The teacher would prepare physical things such as toys, supplies for school or other physical objects. While intangible prizes are activity rewards that give more satisfaction on the students, such as becoming a line leader or the teacher's assistant, being a team leader during activities or having certain privilege that singles out the student from others.

\subsection{Function of Reward}

The use of rewards in the classroom situation helps teachers improve student motivation in learning. Reward provides information about one's abilities when related to real success or development, such as when an instructor commends students for learning new skills or gaining new knowledge [9]. [10] points out that classroom rewards can be beneficial. Referring to the above argument, when a teacher offers a reward, students can be correlated with behaving and acting in a feeling of pleasure. Typically, students are going to do something that constantly activates reward. Besides, reward is intended to make students do all they can to raise the score more faithfully. Rewards can be 
a successful way to inspire students to do so which motivate the students to become involved in learning.

\subsection{Types of Punishment}

Educators often select punishments if the students do not follow the rules after setting out the rules at the beginning of the year and listing the punishments. Penalties or consequences usually involve holding something that students enjoy. A disruptive may, for example, be held in recesses or detained after school. A student who often distracts his peers will be disappointed if he knows that at the end of this month he will not receive class treatment.

[3] mentioned that there are two kinds of punishment: positive and negative punishment. The difference between the two might be difficult to tell.

a). Positive Punishment

Positive penalty is a penalty which aims to lower the rate of any unwanted behavior. The concept works by presenting the individual with a certain negative impact once an unwanted behavior has been shown. If a person has a negative effect, in the future the person is less likely to repeat the same behavior. Some good punishment is that students who do not do their homework, clean the public facilities or garden for their lateness.

b). Negative Punishment.

Negative penalty is part of the deterrence, and often helps to lower the rate of any undesirable behavior. It works by removing certain favorite objects from the life of the person. When a certain desired stimulus/ item is eliminated from the life of an individual, the undesired behavior is shown, and there is less chance of the behavior occurring again in the future.

The word 'negative' sounds very repetitive, because punishment is often the product of negative outcomes. As positive punishment tends to add a stimulus to the individual's life, negative punishment means eliminating a certain favorite object or stimulus from the individual's life. Such examples of negative discipline are tossing away students with an eraser if they're noisy, threatening students with rulers if they don't follow the rules, and excessively irritating students for no apparent purpose.

Meanwhile, [7] points out that positive punishment means adding something that triggers the reduction in the repetition of behavior shown. Negative penalty, also known as deletion fines, occurs when a behavior occurs after a positive occurrence or consequence is eliminated. Example: a child teased his sister, making her cry so loudly. Because of this, his mother spanked him. The boy has never mocked his sister again. On the other hand, it is the removal of something that is favorable, in order to reduce the recurrence of the behavior. Example: A teenager is caught cheating on a test. Then his parents forbid him to use car and cut his allowance. The teenager is no longer cheating on his current exams.

2. Kinds of Punishment

[11] divides punishment in four:

a) Psychical punishment
It includes slapping, pinching, and hitting. For centuries, this type of punishment has been applied mostly in the field of non-education. At present, this kind of punishment is rarely applied in the field of education. Except for gym classes, this kind of physical exercise is rarely used. In fact, this is a good punishment to make students avoid some kind of misbehavior. Also, this punishment may scare students from failing to achieve the objectives.

b) Words and sentences

This kind of punishment includes some homework or written assignments that students have to as a penalty of misconduct they have committed. Summarising certain pages of a book, for instance, is a kind of words based punishment.

c) Stimulus psychical punishment

The teachers commonly give this kinds of penalty immediately to the students. In class, some students may engage in misbehavior in such a way that the teacher uses physical stimulus punishment, such as the use of slope, wide-opened eyes, and glum expression to threaten (punish) students toward their actions.

d) Inconvenient punishment

Teachers can use this form of discipline to make the students feel uncomfortable, such as asking the students to stand up in front of the classroom, leave the classroom, stand or sit beside the teacher. Writing a sentence and rewriting for 10 or more times may be another option for the teacher. This is intended to make the students consider about their wrongdoing.

\subsection{The Effects of Rewards and Punishment}

Some studies have been conducted in several contexts investigating the effects of reward and punishment on students' learning. A study was done by [12] looking at several aspects of rewards and punishment practiced by teachers in Surakarta. In his research, the award was given because the students had shown progress in their efforts by giving some interesting gifts, applause and expression and a high score to the students. Regarding the punishment implementation, kinds of punishment implemented were self-introduction in front of the class, singing in front of the classroom and squad jump. The punishment given because the students less than the maximum for his efforts.

This study further reveals that giving rewards and penalties provide contribution in teaching English and have automatically get positive responses from the students. Because of the rewards and punishment, the students have been more enthusiastic in learning. They found learning activities as fun, happy and exciting. They also looked more motivated and more diligent to study English. However, The students' responds on the use of punishments in teaching English, students are embarrassed, students are less optimistic and worried about it.

Another study was conducted by [1] from Lunghwa University of Science and Technology, Taiwan, ROC. He looked at how rewards and penalties affect the motivation of students involved in the learning process and changes their behavior. The objectives of this research was also to examine the characteristics of reward and penalty systems in four schools in the Philippines and the perception of 
students about the effectiveness of systems currently in use. The participants of the study were the first-year high school Chinese students. Questionnaires, interviews and observations were used to gather information about the participation of the students with learning, social control, and rewards and punishments policies. Results revealed that, although the school policies managed to link the rewards and penalties system to a positive discipline strategy, the emphasis in practice often seemed to be on punishments for bad behavior rather than increasing engagement and motivation. Students tended to see rewards strongly linked to work and penalties for behavior.

[13] also conducted a study on the application of rewards and penalties for motivating junior high school students to learn English in Bandung. The data were taken from interviews, observations, and questionnaires. This study shows that the teachers' kinds of rewards in English learning were verbal and tangible rewards. Whereas punishments were practiced in the forms of verbal, action, and penalty punishments. This study also indicated that the students responded positively to rewards and penalties when they were properly delivered. The result shows that when rewards were properly applied, the motivation of students could be enhanced. In addition, the proper implementation of penalties may also improve both the student's discipline and the enthusiasm for learning English. This study suggests that the appropriate use of rewarding and giving penalties might be an alternate solution to enhance student motivation. Another study by [14] also indicate similar findings that rewards and punishment did well in motivating students to have higher achievement.

Although many studies show that the use of rewards and punishment has shown lots of benefits in imprving students' motivation and achiement, as study by [15] reminds us that the effects are just temporary. His study investigated the use of rewards and punishments and how these have impacted motivation of 25 6th grade students at elementary schools in Phoenix, Arizona. The study revealed that students' behavior changed or retruned back to its initial state when the teacher did not provide rewards and punishments anymore. Again, this study shows that the effects of rewards and punishment should be mantained with some follow up learning activities.

\section{CONCLUSION}

This paper has explored how existing literature discusses the notion of 'rewards and punishment' in the context of learning and how the rewards and punishment could affect students' learning theoretically. This paper has also reviewed what sort of activities teachers can do to implement rewards and punishment in a proper way. To answer these questions, a so-called 'library research' activity has been conducted. This was done by browsing, reading, and critically reviewing some related secondary sources such as books, journal articles. This study found that theoritically rewards would increase students motivation, so they can learn and work harder. The rewards and punishment will also increase students' interest in a particular subject. This will lead to a stituation where rewards can motivate students to have a good performance. In conclusion, this study indicate that rewards and punishment, if implemented wisely, would bring a lot positive effects on students motivation and performance.

\section{REFERENCES}

[1] G. S. Ching, "Looking into the issues of rewards and punishment in students," Int. J. Res. Stud. Psychol., vol. 1, no. 2, 2012.

[2] R. E. Slavin, "Educational Psychology: Theory and Practic, (5th Edition)," Needham Height. MA Allyn Bacon, 1997.

[3] F. N. Jones and B. F. Skinner, "The Behavior of Organisms: An Experimental Analysis," Am. J. Psychol., 1939.

[4] G. R. LeFrançois, Theories of Human Learning. What the Professor Said. 2012.

[5] P. Holth, "Two definitions of punishment.," Behav. Anal. Today, 2005.

[6] B. E. Skinner, "The experimental analysis of behavior," Am. Sci., 2012.

[7] S. M. Sincero, "Operant Conditioning," Explorable.com, 2011. [Online]. Available: https://explorable.com/operant-conditioning. [Accessed: 20-Oct-2020].

[8] J. S. Carton, "The differential effects of tangible rewards and praise on intrinsic motivation: A comparison of cognitive evaluation theory and operant theory," Behavior Analyst. 1996.

[9] C. Kyriacou et al., "Motivation in Education: Theory, Research and Applications," Teach. Dev., 2008.

[10] J. W. Santrock, "Educational Psychology 5th Edition," Educ. Psychol., 2011.

[11] Herman, Interaksi dan motivasi belajar mengajar. Jakarta Barat: Rajawali Press, 1980.

[12] A. R. Hakim, "The Implementation of Rewards and Punishments in Teaching English at Ninth Grade Students of MTSN 2 Boyolali," IAIN Surakarta, 2018.

[13] P. S. N. Pebriani, "The Implementation of Rewards and Punishments toward Students' Motivation in Leanring English," Universitas Pendidikan Indonesia, 2013.

[14] L. M. Wilson and D. A. Corpus, "The Effects of Reward Systems on Academic Performance," Middle Sch. J., vol. 33, no. 1, pp. 56-60, Sep. 2001.

[15] Bryan D. Matera, "The Effects of Rewards and Punishments on Motivations of the Elementary School Student," Walden University, 2010. 